University of Wollongong

Research Online

Faculty of Social Sciences - Papers (Archive) Faculty of Arts, Social Sciences \& Humanities

2016

Preservice teachers' learning with Yuin Country: becoming respectful teachers in Aboriginal education

Anthony D. McKnight

University of Wollongong, anthonym@uow.edu.au

Follow this and additional works at: https://ro.uow.edu.au/sspapers

Part of the Education Commons, and the Social and Behavioral Sciences Commons

Research Online is the open access institutional repository for the University of Wollongong. For further information contact the UOW Library: research-pubs@uow.edu.au 


\title{
Preservice teachers' learning with Yuin Country: becoming respectful teachers in Aboriginal education
}

\author{
Abstract \\ The ownership of Aboriginal knowledge and the Aboriginal perspective presented in school curriculum is \\ always with Country. A number of preservice teachers were taken to a sacred story, "Gulaga a Living \\ Spiritual Mountain," to participate in an elective subject to engage in respectful reciprocal relationship \\ with Country. The spirituality of Country is unknown to many preservice teachers, consequently the \\ concept of Country as teacher in a respectful reciprocal relationship was unfamiliar. Engaging in \\ Aboriginal ways of knowing, learning, and behaving provides an opportunity for preservice teachers to \\ initiate a relationship with Country to respectfully implement Aboriginal perspectives in their own \\ teaching. This article not only examines how preservice teachers developed a relationship with Country, \\ but also importantly demonstrates how a relationship between Country, researcher, all the participants, \\ and the research can inform respectful behaviour in reculturalising Aboriginal perspectives.
}

\section{Keywords}

becoming, respectful, aboriginal, preservice, education, teachers, learning, yuin, country

\section{Disciplines}

Education | Social and Behavioral Sciences

\section{Publication Details}

McKnight, A. (2016). Preservice teachers' learning with Yuin Country: becoming respectful teachers in Aboriginal education. Asia-Pacific Journal of Teacher Education, 44 (2), 110-124. 


\title{
Preservice Teachers' Learning with Yuin Country: Becoming
}

\section{Respectful Teachers in Aboriginal Education.}

\begin{abstract}
The ownership of Aboriginal knowledge and the Aboriginal perspective presented in school curriculum is always with Country. A number of preservice teachers were taken to a sacred story, Gulaga a living spiritual Mountain, to participate in an elective subject to engage in respectful reciprocal relationship with Country. The spirituality of Country is unknown to many preservice teachers, consequently the concept of Country as teacher in a respectful reciprocal relationship was unfamiliar. Engaging in Aboriginal ways of knowing, learning and behaving provides an opportunity for preservice teachers to initiate a relationship with Country to respectfully implement Aboriginal perspectives in their own teaching. This paper not only examines how preservice teachers developed a relationship with Country, but also importantly demonstrates how a relationship between Country, researcher, all the participants and the research can inform respectful behaviour in reculturalising Aboriginal perspectives.
\end{abstract}

Keywords: Aboriginal perspectives; Country; experience; preservice teachers; Communities; partnerships.

\section{A respectful and localised Aboriginal approach to teaching and research}

Yuin Country provides an original story to welcome preservice teachers in their learning of a respectful reciprocal relationship with Country. In 2012, a number of Early Years and Primary preservice teachers from the University of Wollongong (UoW) were taken to this story, Gulaga. Gulaga is a living spiritual Mountain that offered a Yuin teaching legacy (gift) through an Aboriginal lecturer working with community members to produce a unique Aboriginal education elective subject, Engaging Koori Kids and their Families. Gulaga is our Creation Story that holds many of the totems that connect us all. Gulaga is my Mother that provides me with a cultural recharge every time I visit whether, physically, mentally or spiritually. This paper will occasionally shift in voice (writing) to help the reader see the personal relatedness, not just to culture but also to the writing in academia to 
maintain the voice of researcher and Country. The elective subject was designed to engage the preservice teachers in a localised Aboriginal way of knowing, learning and behaving. The Yuin localised approach went beyond the Western colonial educational policy structures imposed on mandatory Aboriginal Education core subjects that are now part of the majority of preservice teacher education programs in New South Wales. This paper explores spiritual connections when preservice teachers are exposed to Yuin ways of knowing, learning and behaving. The term spiritual for the context of this paper is not intended in a religious manner. Spirituality from my current Yuin position is an appreciation of everything that is inherent of Country, a connecting energy that provides oneness of being. Therefore to diminish spiritual damage, the paper will focus on the building of spiritual connections between Country and preservice teachers. This differs from an approach and paper concentrating on the preservice teachers that resisted forming spiritual connections or who interpreted Country in terms of colonised aesthetic notions of the beauty of the South Coast of NSW.

Aboriginal approaches to research should be story (spiritual) based and not founded solely on Western theoretical positions (McKnight, 2013; Black, 2011). Smith (2012) advocates for important elements of Indigenous research that connect with, and differ from Western research agendas. The connection is the 'good' created for society by Indigenous and Western research agendas. While the difference is the use of specific terminology in Indigenous research such as healing, decolonisation, spiritual and recovery Smith, 2012). The research focus in this paper is therefore subjective and interconnected because Country, the Aboriginal researcher, all participants, 
the entirety of the research and the elective subject are relational. Wright, Lloyd, Suchet-Pesrson, Burarrwanga, Tofa and Bawaka Country (2012), describe their research as co-becoming with Bawaka Country as "knowledge generated with humans and nonhumans at, through and with Bawaka ${ }^{\mathrm{i}}$. Bawaka is in our stories, and our stories are in Bawaka" (p. 53). Research as story from my localised Aboriginal position derives from Yuin Country, as this is where Aboriginal knowledge production takes place in a oneness of knowing and learning. The holistic Aboriginal approach or oneness relationship to the research, the elective subject and the writing of this paper is dynamic: 'it' has its own life. Country decentres the human authorship privilege of overseer, creator, controller, implementer and owner to provide opportunities to reimagine and co-create how we think about and practice knowledge (Bawaka Country, Suchet-Pearson, Wright, Lloyd and Burarrwanga, 2013). The important understanding to be instilled in a respectful reciprocal relationship with Country as teacher and writer with teachers and readers is that the localised Aboriginal Country maintains ownership of the knowledge, approach and process.

The localisation of Aboriginal knowledge and doing is paramount to deproblematize preservice teachers' interaction with Aboriginal perspectives. The preservice teachers in this study did not learn to teach Aboriginal culture but unearthed their own initial interconnecting spiritual story with Country. Thereby the preservice teachers re-imagined, felt and produced a spiritual understanding and perspective that demonstrated their relationship with a localised Aboriginal experience with Country as teacher. Many preservice teachers and practicing teachers' understandings of an Aboriginal 
perspective in relationship with Country are very limited; they cannot see or hear Country. Harrison (2012) states, "there is a sense of frustration among many teachers, given their self-confessed ignorance of Aboriginal people and cultures, over how they could teach Aboriginal perspectives outside the Imaginary figures created for them" (p. 6). Harrison argues that teachers create their own image of what they want Aboriginal people to be, and this is manipulated by the 'Imaginary figures' created by the media and Western historical romantic influences. Teachers are caught in Western dualistic thinking of the 'Other' (non-Aboriginal/Aboriginal) that focuses on difference. Thereby the Western strategy to remove the cultural difference in Western education system is the process of assimilation, to create what is a corrupt concept of 'sameness'. The Yuin 'there is always two' in existence examines similarities and connectedness (McKnight, 2013) as everything is in oneness. From a Yuin storying standpoint, shared through the Yuin Ancients legacies, everything is born from the Mother (Minga). Everything is therefore connected by birth through varying relationships. The Mingadhuga Mingayung (My Mother Your Mother) approach (McKnight, 2013) introduced the preservice teachers to an interrelating relationship, Country as Mother who holds knowledge of interacting relationships. This oneness approach also informs this paper, the research and elective subject to find cultural connections through storying. This paper emphasises the well-known importance of schools having strong partnerships with Aboriginal people. However, it will extend this partnership to include the 'other' extended family members and communities from Country to show how Country can be seen as a teacher in classrooms. 
The prominent concept explored in the research and in this paper is how a relationship with Country can occur in the same way as a relationship with another person. As Bawaka Country et al (2013) explore from a Country (Story) and natural resource management theoretical approach:

Humans care for Country as part of Country, not as a separate from it. Acknowledging Bawaka Country as author is part of our responsibility as Country, is part of our caring for Country and caring for ourselves. In caring for Country, humans care for themselves; in caring for humans, Country cares for itself. (p. 186)

Country cannot be seen in the same light as 'the environment', in which humans place their own meaning of place in labelling the landscape. Country is a living fusion of living entities, including Mother Earth, and like any human she has roles and responsibilities, so that people must ask of a particular Country/place, 'who are you?' For many people this can be challenging, so removed as it is from their previous engagement with the land, its entities and their Western ways of learning. Thereby self in this paper is the human examining the umbilical cord of connection (McKnight, 2013) that connects self (human) to Country (non-human) and Country to self. Bawaka Country et al (2013) recognise this concept within an Indigenous ontology of 'co-becoming', "this is a deeper ontological commitment, to really, really take seriously our existence as part of the world" (p. 188), as we are of and are Country.

\section{From a mandatory Aboriginal Education subject to an elective subject}


In 2005, the NSW Minister for Education and Training finally, after many decades of lobbying (Mooney, Hals, \& Craven, 2003), made the decision to mandate Aboriginal Education in all NSW Teacher Education Institutions. This was in response to the many National reports and reviews (Craven, Halse, Marsh, Mooney \& Wilson-Miller, 2005, Hughes 1999, McRae et al 2000, Mellor and Corrigan, 2004) that pointed to the need to support preservice teachers in addressing educational disadvantage for Aboriginal students in Australian schools. As Price (2009) states in an Australian Federal government paper:

Pre-service teachers have the right to experience a sound education that will equip them to be successful teachers of Aboriginal and Torres Strait Islander students. (quoted in McRae et al 2009, p. v)

The NSW Institute of Teachers' Mandatory Requirements incorporated this policy shift into requirements for the accreditation of university programmes of teacher education (NSWIT, 2007). The NSW Institute of Teacher Education (2007) indicates the key elements to be covered within the mandated Aboriginal Education subject:

Teachers need to understand Aboriginal history and its significance for the diversity of Aboriginal cultures and perspectives. Teachers need to demonstrate understanding and knowledge of the specific learning needs of Indigenous students in rural and urban settings. They need to understand what constitutes racism and anti-racism strategies, policies and 
legislation and have an awareness of the key stakeholders in Aboriginal education. Teachers need to understand the impact of culture, cultural identity and diversity in schooling, specific culture and language learning needs of Aboriginal students and appropriate teaching strategies. (p. 2)

As a result of the NSWIT requirements most universities in NSW included mandatory Aboriginal Education in various subject formats in their primary and secondary teacher education programs. At the University of Wollongong, Faculty of Education, a mandatory core subject was developed and instituted in 2009. A central theme throughout the mandatory Aboriginal Education subject was a localised Aboriginal approach where Aboriginal and non-Aboriginal people work together to shift Western education's organisational culture. As "each clan and community of Aboriginal people has developed their own special ways of being, knowing, doing things and saying things that are unique to their people and communities" (DET \& AECG, 2004, p. 202), it was important that the preservice teachers understood and engaged in the local Aboriginal system to help enhance the future for all students. The majority of the UoW campuses in N.S.W are situated on Yuin Country that "[e]xtends from the Snowy River in the South to the escarpment of Wollongong, our northern boundary, and then out to the Southern Tablelands.” (Harrison \& McConchie, 2009, p. 15). Yuin Country therefore informs the localised approached for the mandatory Aboriginal Education subject, the elective subject and the research for this paper.

Mandatory Aboriginal Education subjects provide a good theoretical venue and introduction into Aboriginal educational academic discourse. However, 
if the educational benefits derived from Aboriginal Education mandatory subjects are to enrich and be embedded in preservice teachers' understandings, additional Aboriginal elective subjects are required to enhance opportunities for localised cultural interactions. A constraint of the mandatory core subject at the University of Wollongong, and likely for most similar subjects in teacher education programs in Australia, is the large number of enrolments (300 approximately each year). This substantially restricts the concrete personalised experience with Aboriginal community/ies needed to incorporate holistic Aboriginal perspectives into the curriculum. The 'skill set' for preservice teachers in relation to Aboriginal education and perspectives needs to be initiated through the whole "process, values, protocols, systems" (Lowe \& Yunkaporta, 2013, p. 3) of engaging with the Aboriginal Country's cultural families and communities. If we were to incorporate such an approach into the mandatory subject, the respect protocols that are required and the physical numbers of preservice teachers would place further stress on Aboriginal members from the community who are already overworked in supporting and challenging Western educational institutions and practices. I would argue that a number of processes, protocols and funding procedures need to be implemented to counteract these restrictions, but this is not the purpose of the paper.

In 2010 the Engaging Koori Kids and their Families elective subject grew out of the 2009 implementation of the University of Wollongong's mandatory Aboriginal Education core subject. The elective subject was designed to extend the preservice teachers' knowledge and understandings of Aboriginal ways of knowing and learning to build skills for teaching in 
and working with Aboriginal children and young people. This was achieved through a partnership with Yuin Country, Elders and the Faculty of Education's Aboriginal staff members. Due to the more intimate nature of the elective subject, the capacity to apply more intensive Aboriginal pedagogical practice in partnership with the local communities to enhance preservice teachers' 'skill sets' became more achievable.

\section{Reinstating Yuin Country as knowledge holder through storying}

Engaging Koori Kids and their Families ran over second semester in the final year of an Early Years and Primary teacher education program. It included visits to: Gulaga; an Aboriginal Mission; and a local primary school. The field trip provided an opportunity for preservice teachers to meet, engage and learn with Yuin Country. Yuin people's family and primary carers Mother Earth, Father Sky, Grandmother Moon and Grandfather Sun were introduced and taught within the experience. These communities birthed and raised by the Yuin primary carers had the leading roles in the preservice teachers' teaching. The communities included human, tree, bird and many other communities of Country that revealed themselves. The principal teacher and major director of the whole elective subject and research was Gulaga, Mother (Minga) Mountain through a Mingadhuga Mingayung (My Mother Your Mother) approach (McKnight, 2013).

The preservice teachers that participated in the elective subject experienced first-hand a Yuin Way of knowing, learning and behaving. Gulaga is a culturally significant Mountain and Dreaming for Yuin people on the far South Coast of NSW. Gulaga 'holds' the gift of story and with the help of an Elder guided the preservice teachers to understand the three Ancient Yuin 
principles of learning: "Watching, Listening and Seeing" (Harrison \& McConchie, 2009, p. 59). The purpose of the subject was to initiate learning from Country to enhance preservice teachers' skills, knowledge and understanding in order to place Country central in the process of implementing a holistic Aboriginal perspective.

The preservice teachers were taught to observe and experience Country's silent Stories of knowing, learning and behaving. Country was teaching/taught the preservice teachers without voice so they could be 'learners', then, in turn, teachers of their own learning journey in the context of Yuin ways of knowing, learning and behaving. The preservice teachers engaged in a relationship of learning with Country to know self in this relationship of becoming a community member of Country.

In 2012, the elective Engaging Koori Kids and their Families had 25 enrolments with eight Early Years and 17 Primary final year preservice teachers. Twenty (seven Early years and 13 Primary) out of the 25 preservice teachers enrolled in the subject 20 agreed to participate in the study. This cohort included sixteen women and four men. Permission was granted by the Elders to take the preservice teachers to a number of relevant 'educational sites' and to participate in cultural ceremonies. During a two day field trip the preservice teachers visited a school that was recommended by an Elder that worked closely with her and other local Aboriginal community members. The preservice teachers were then taken to an Aboriginal mission and introduced to the Aunties: Elders (representing Mother Earth and Grandmother Moon) who shared their stories of education, culture and importance of respectful community/school partnerships. In 
addition the female Elders triggered the emotional aspect of the learning connected to Country. The Aunties introduced the local 'Community and Country' literally as in 'place', people and spiritually as in the 'broader' community as well, for example, the Mothers of Aboriginal children, the River, the Mountain and the Mission itself.

Aboriginal Men and Fathers who were selected by the Elders to represent Father Sky, prepared the preservice teachers for two public ceremonies and Gulaga. One of the ceremonies was introducing the preservice teachers to Grandfather Sun so they have the potential to see the Stories. The preservice teachers met Gulaga, Mother Mountain and experienced her Stories, Families, Communities and protocols. The Stories were explained by a Grandfather and Yuin Elder Uncle Max Harrison on Gulaga, who further impressed the energy from the stories into/to the preservice teachers, who were open to the teachings. The preservice teachers' experience was further enhanced and consolidated by exploring the teachings from Country through reflection and extended activities with Country intended to inform classroom practice. Activities back at the university were designed to encourage the preservice teachers' self-examination. These included the production and presentation of their own stories (gifts) constructed from the experiences via their interpretations of Aboriginal literacies: song, dance, art and storytelling.

\section{Researching an Aboriginal Education elective}

A research study was designed around this elective subject, with the explicit aim to investigate the preservice teachers' learning journey in Aboriginal ways of knowing, learning and behaving. I, as an Aboriginal man, have 
been immersed in this way of learning and engaged in a 'reading' of the data, as I would have 'read' the teachings from Country; seeing or reading Country talk without voice (Harrison \& McConchie, 2009). Instead of reading the teachings straight from Country I observed how Country was working within the preservice teachers' stories and yarnings. Metaphorically I examined the trees that were being reflected in the water of a creek, looking at all the connections. The research used a qualitative approach based upon a Yuin Mingadhuga Mingayung storying (McKnight, 2013) paradigm that could not be separate from the elective subject or additional methods. UoW Human Research Ethics Committee approval was granted for the research. To protect the consenting participants their names have been changed to maintain anonymity.

A yarning (Bessarab \& Ng'andu, 2010) method was also utilised in the elective subject to help the yarning and storying process to be understood and develop as a teaching skill. Developing an understanding of yarning and storying helped the preservice teachers to produce deep and rich data to verify what was happening to their everyday lives in relation to learning from Country. To achieve this, the Aboriginal researcher, together with a paid research assistant who had experienced a cultural visit to Gulaga, conducted pre and post elective group yarning discussions and the Aboriginal researcher examined the stories (Smith, 1999) that each preservice teacher told of his or her connection to Country. The preservice teachers' stories were shared in a group situation before conducting the post elective subject group yarning discussion. A Western thematic analysis was also employed to assist in identifying themes in the data and Mingudhuga 
Mingayung helped to bring the data into relatedness, with Country as the knowledge holder.

I, as the Aboriginal lecturer and researcher, acted as an observer participant to guide the learning experience and to observe the preservice teachers' behaviour in relationship with Country and themselves. As a researcher, I used the preservice teachers' response to the pre and post elective subject group discussion with their stories to see a number of truths within their relationship with Country. As Kwaymullina and Kwaymullina (2010) state, "every story is true, within its own space. It is the physical and metaphysical context of country that shapes all meaning" (p. 202). My own cultural relationship with Country allowed me to explore my connections and similarities to the preservice teachers' growing relationship with Country. This relationship helped me to identify the nature of the preservice teachers' understanding, knowledge and pedagogical skills in relatedness to Country.

\section{The pre and post subject group yarning discussions}

A Yuin Yarning method was employed to maintain Country's integrity as a cultural practice. It was used to assist in identifying the knowledge that the preservice teachers gained from their experience in the context of the Mingadhuga Mingayung approach. Bessarab and Ng'andu (2010, cited in Geia, Hayes \& Usher, 2013) explain "yarning” as an informal and relaxed discussion creating a shared journey through a relationship. As Bessarab and Ng'andu (2010) state:

One of the challenges for qualitative researchers when listening to stories of lived experience is that the teller decides what parts 
of their story to tell and which parts to leave out, the researchers $^{\text {ee }}$ role is to draw out the parts they are interested in which may not be told and which relate to the research topic (p. 38-39)

To try and overcome this challenge it was important to connect the extension of the story question with Country. This was usually achieved by telling a story in response to a story. This approach can trigger more information to be shared. The pre and post group yarning discussions provided the nexus and Aboriginal locus for the research. The yarning method in the elective subject and research continued to move the research dynamic towards Aboriginal reculturalisation of knowledge and research. At the same time it provided data about preservice teachers' understanding in their shared relationship journey with Country for analysis.

I conducted the interviews with the assistance of a female $\left(\right.$ Sister $\left.^{1}\right)$ research assistant who, as well as having experience Gulaga, had experienced yarning circles. The yarning approach allowed the research assistant to share her own experience of Gulaga to enhance an open two-way cultural sharing environment during the discussions. The key question asked in the pre and post yarning sessions was: "What does the term Country mean to you?" This began a discussion process, which took time to develop yarning is about settling into each other's spirit. For example, in the pre subject interview, the preservice teachers did not really know each other and seemed to find it more difficult to connect on such a deep level so that

\footnotetext{
${ }^{1}$ Sister in this context means a non-Aboriginal woman who understands that spirit is not black nor white, it is one in the same.
} 
yarning was limited. As Block (2009) describes "our isolation occurs because Western culture, our individualistic narrative, the inward attention of our institutions and our professions, and the messages from our media all fragment us" (p. 2). In the post subject interviews, I observed a more unified group that were more comfortable with each other to share what they felt. Preservice teachers commented after the field trip that they felt like they know belonged to a little class community (McKnight, Observation notes). This was also evident in the length of the preservice teachers' responses and the greater depth in expressive language to describe what they had learnt.

\section{Storytelling: Preservice teachers' Story}

One of the assessment tasks for the elective subject was the construction of a story about the preservice teachers' experiences and understandings of forming a connection with Country. The story could be presented as either an artwork, written story, poem, song or dance. This task was pivotal to the research as it provided a snapshot of what occurred in the preservice teachers' learning journey as they thought through what it meant to teach an Aboriginal perspective drawing on Aboriginal pedagogical approaches.

\section{Analysing the data}

My Aboriginal understanding of Gulaga's storying allowed me to identify the ways Gulaga's stories worked as teacher in the preservice teachers' use of language in their yarnings and storytelling (McKnight, 2013). A thematic analysis was also used to work with the 'Yuinised' methods to show the patterns of language similarities or themes within the preservice teachers' stories and yarning discussion responses. 


\section{The preservice teachers' learning journey}

The analysis of the preservice teachers' storying identified three key points. Firstly the analysis of the data identified a clear shift in the preservice teachers' use of language in their knowing and appreciation of Yuin Country. Secondly the analysis demonstrated how Country was active through the sharing dynamic to produce intertwining cyclical relationships. The third key point focused on the shift from telling a story, to the teaching skill of respectfully sharing a gift of knowledge in relationship with Country.

\section{Recognising and appreciating Country}

The preservice teachers' answers, in the pre elective subject focus group discussion, to the initial question, "What does the term Country means to you?" indicated that the UoW core Aboriginal Education subject completed the previous year had influenced their responses. The preservice teachers' wording in the following quotes reflects an interpretation of my teaching about Country as connection and relationship to the land.

Connection that you have with a place. (Sharon)

When I think about it. I think about surrounding areas, the nature and surrounding, that is my first thought that came to mind. (Meg)

A place of significance and your connections with it and what you make of it. (Kylie)

Two other preservice teachers signposted a spiritual element to Country that encompasses everything, with the use of the terms 'guess' and 'think' 
indicating a tentative understanding. An individualised response was also represented by the use of the words, 'I' and 'you'.

I guess there is like heaps of different ways you can go, you can look at it in terms of the score, in terms of like spiritual. So in the spiritual sense I guess it would mean, you feel that you belong. (Fred)

I always think of it being everywhere. It is everywhere not a specific place or area necessarily. (Pat)

Country is described objectively via a taught definition and the participants' language suggests their understanding does not include an emotional or personal connection. This analysis however points to apparent deficiencies when there is another possible interpretation. In conversation with me following the pre subject discussion, the research assistant observed, the preservice teachers seemed very open to learning more and appeared not to want to be disrespectful in their answers. This behaviour from an Aboriginal standpoint demonstrates the respectful behaviour required so that gifts of emotional learning can be shared in a two way process. The above answers to the initial question suggest a well-intentioned intellectual and un-emotive viewpoint. In addition none of the comments included any language to indicate their own relationship with Country. From my observations of the first yarning interview the responses appeared to be a more formal and a natural nervousness to being interviewed. The answers were brief, restrained and individualised statements of their own understanding, not a shared conversation that grows from yarning. The newness of the group to each 
other was also likely to have been a factor in restricting yarning; understandably they 'stayed' within their own safe and known Western understanding of an interview and how the system works in separation or deficiencies.

The post subject discussion responses to the question about the meaning of Country provided evidence of the preservice teachers' journey in the context of the Mingadhuga Mingayung story. Their talk was more descriptive and inclusive of Country, rather than defining Country. The sharing of a gift of knowledge from Country shifted the analysis as well to find connections and the preservice teachers gifts of sharing emotional learning. At this stage the preservice teachers were well rehearsed in how yarning operated and seemed much more relaxed and open. The quotes below reflect this shift in their relationship with Country in relation to self. The language utilised was more personal, inclusive and emotional.

Everybody has a different connection, I think we saw through our $[\mathrm{xxx}]$ session they [others' responses] were all very very different. We were connected to the land for different reasons. (Clair)

Listening for its messages and the way it talks to you and communicates with you, it can be really subtle, it can be a smack in your face but it tells stories to help you understand what is happening or help you calm down or refocus, it is all about looking after and listening to it. It energises me as much as I energise it. (Meg) 
The preservice teachers were more definite in their language and 'we' replaced ' $I$ ' in a number of the responses. The gift from Country and the gift of responding back to Country are significant, as McKnight and Block (2010) state, "as we share gifts, all kinds of new connections and relationships are created" (p. 123). The language in response to the gift from Country seemed to be more about relationships and connections. The last comment indicated recognition that the relationship goes even further with Country being a communicator and healer with the spiritual element being reinforced with the term 'energies'. Furthermore the use of the term 'we' indicates a sense of togetherness between the participating group and the 'we' as in Country and Self. This sense of 'we' was evident from the individual stories, yarning discussion and observations by the researchers that the group had also established strong connections with each other. I also observed a sense of warmness in the preservice teachers' voices and body language when talking about Country that was not there in the pre elective interviews.

The following statement clearly demonstrates another dimension to the preservice teachers' relationship with Country as that of teacher.

I think it is something that teaches us, we learn a lot from Country, it has a lot of lessons it holds and imparts onto us. (Gabby, emphasis added)

Furthermore, the importance of 'listening' for Country as teacher, and being in a relationship for this to occur was recognised. For example, as Mel explained, 
It is always changing, always different stories and if you are in tune or even open, your eyes can see it, it is clear as day. (Mel)

Hidden within the above comments is Country's voice and how it was sharing knowledge within the individuals through their own expressions of meaning with terms such as 'in tune'. As Bawaka Country et al. (2013) point out this is a process, which involves "sharing understood in a relational and more-than-human way" (p. 186). The terminology used by the preservice teachers in the post elective yarning interviews indicates that some of the preservice teachers had started to understand how Country utilises varying unseen and seen energies to communicate. In these interviews, yarning occurred more extensively and the sharing of knowledge and understanding of their relationships with the Mother was strengthened through each other's story.

While this recognition of Country and shifts in relationship are beginning steps to Yuin ways of learning, nonetheless I argue the post elective yarning discussion comments convincingly demonstrate the preservice teacher's positive and emotional engagement with Country. Their comments clearly confirm that the preservice teachers listened to the Elders, the Aboriginal lecturer and 'community members' with an open mind to the ancient pedagogy in action of watching, listening and seeing.

\section{Sharing connections to Country}

The analysis of the preservice teachers' stories reinforced the influence Mingadhuga Mingayung had on their understanding of a respectful relationship. The atmosphere of the story presentations was 'electric' as the 
preservice teachers shared and listened to each other's stories. The laughter, the applauding and the positive appreciation displayed in the room demonstrated how the group had connected through Country's teachings. At the same time the sharing of their stories was a reciprocation of the teachings through storytelling as they creatively expressed their connective/ed relationship with Country. Storytelling through Yuin Country stories is an important pedagogy that personalises learning and respect. In the quote below this is described by Dhängal in the context of Yulnu Country (2008):

I'd teach students to really know about themselves, who they are, to see things which are good about that's within themselves, to know who each person really is, and what they can achieve from the teachings from the Yolnu perspective... (quoted in Guyula, 2010, p. 74)

While the preservice teachers were learning about Country, they were at the same time initiating an examination of self as part of Country, through their reflective stories. The term 'connection' was prominent throughout the preservice teachers' explanations of their story with Yuin Country and in their post subject interview.

I didn't realise I had a special connection to a place (Sharon post elective subject interview)

I found that my connection to Country by opening up to the fact that Country was trying to connect to me, that I realised that it works both ways (Greg post elective subject interview) 
The preservice teachers recognised a connection through Country's teachings, with self, through a particular landscape, as a surprising fact. Sharon's use of the term 'realised' suggests two significant findings: one that the relationship had already been initiated by Country and she was the one not knowing; secondly, that her relationship with Country was real and tangible. Comments made during the preservice teachers' story presentations reinforced the importance of observing the connections with the community members as real, for example, birds as a purposeful teaching and learning method.

So when I am out bush I now acknowledge birds and see encounters with them, situations to be interpreted not just coincidences. (Fred)

It is through the subject that I started to look at Country and not only look at the physical side but look at my feelings and what it meant to me. (Mel)

These comments further emphasise the preservice teachers' accomplishment in understanding the teachings from and learning with Country are not just on a physical level, it is emotional as well. The preservice teachers observed Country talking to them, but just as important the preservice teachers recognised that Country observes them as they communicate with Country. The sharing of the stories as a gift emphasised the reality of the experience, simultaneously establishing the pedagogy of observation to embed a relationship with Country and with each other. 
The majority of the preservice teachers' chose to present their story via an artwork with a descriptive oral story. The other choices included two songs and a narrative. In the preservice teachers' stories there were a number of similarities that indicated deeper connections with the Yuin stories from Mingadhuga Mingayung. For example, the stories identified mutual community teachers, such as trees or birds that impacted on their learning journey. During the individual story presentations a number of the preservice teachers identified with the trees on Gulaga and in turn, their stories connected the trees to their day-to-day lives. The trees were revealed to be very significant:

When I climbed the Mountain I seemed to get an obsession with trees $(\mathrm{Pam})$

While Greg wrote a song about his relationship with the trees formed from his experience:

...Who am I to dig at you, without permission?

How they do I'll never understand,

Cause your a tree and I'm a fan,

Your a tree and I'm a man.

I breathe out,

You take in.

I breathe in what you've given... (Greg)

The sharing of the stories taught the whole group how Greg and Pam felt about the reciprocal relationship that exists with the trees. The declaration 
of the relationship or writing a song indicated the importance of the tree that reciprocates the relationship, just as people do with each other. Importantly Greg displayed the skills of respect, caring and sharing of a story that must be shown to their teacher, the tree/trees. The respect is reciprocated as a teaching skill and part of the non-Aboriginal contribution to the Aboriginal perspective. The sharing through the mind and the embodiment of the tree demonstrated to the group the spiritual connection. The respectful relationship is not a separation because "I breathe out, You take in. I breathe in what you've given" (Greg). The song shows the bond of importance as it uncovered an emotional element in which songs can only do. For example, it placed a spiritual element to the scientific relationship of the human and the tree exchanging gases for each other's survival. Greg can then use this story in song as a teaching skill from Country about the tree into the classroom, by providing respect to Country (including Aboriginal people) as custodians of the pedagogy and knowledge. Just as a preservice teacher should behave respectfully while working with Aboriginal people, as a community member, the tree should also be respected as a holder of knowledge from Country.

To further illustrate the respect skill of teaching with Country, Fred's story shows another strong community connection with clear teachings from Bujarns (birds). Fred expressed his learning experience through a written story on the Black Cockatoo.

Upon returning to the safety of his home the man reflects on what just happened. It occurred to him that the Black Cockatoo was a guiding force, a powerful animal that guided him home. 
What amazed him is that they disappeared when he tried to capture them. He realised that in trying so hard to capture and remember the experience itself he is not really experiencing anything at all. By opening up to the connection that Country was trying to make with him, Country helped him.

This story points to how Fred recognised the spiritual connectedness in relationship, by not trying to control the situation through a 'photo' (capture) to implant his own 'different' Story. The Story was already being told if open-mindedness was accepted by the human participant. The subtle shift away from dualistic thinking challenged but changed the experience for Fred, who has the potential now to utilise this approach in his teaching within the classroom. As this discussion demonstrates, the preservice teachers who participated in this subject can model what they have learnt through their story to describe self in relation to Country through the family and community members' knowledge. The pedagogical journey is now in the hands, hearts and minds of the preservice teachers in connection with Country through a reciprocal respectful relationship.

\section{Discussion and Conclusion: Teaching with a connected heart}

This paper has described an Aboriginal elective subject for preservice teachers that goes beyond the mandatory Aboriginal Education course requirements. The subject, Engaging Koori Kids and Their Families, expanded the preservice students' intellectual insight to a more relational and emotive understanding of Aboriginal ways of knowing and learning. The main intention of the elective subject was for the preservice teachers to 
experience a respectful relationship in order to learn from Country. The avenue into Country was with Mother Mountain, Gulaga. Gulaga was the central entity that informed the elective subject, the research approach Mingadhuga Mingayung (McKnight, 2013), this paper's findings and future research explorations. The elective demonstrated how teachers could implement and contribute to a holistic localised Aboriginal perspective originating from Country. This will enhance their capacity to be successful and skilful educators in Aboriginal Education. From a Yulnu position teaching with Country, Yiniya a Yulnu teacher states it is "different to the education you get in the classrooms because the classrooms don't talk to you" (cited in Guyula, 2010, p. 71). The aim is that preservice teachers take their story learnt from Country from outside the classroom into the classroom. Each preservice teacher then has the skills to work with a range of Aboriginal community members to take their school students outside the classroom to see the relatedness of Country. As Kwaymullina and Kwaymullina (2010) state: "Nothing exists in isolation. All life and everything is alive in an Aboriginal worldview - exists in relationship to everything else" (p. 196). Preservice teachers placing themselves in a respectful relationship by sharing their experience of relationship with Country is crucial to the living relationship within Western education. The preservice teachers were able to tell a personal story to contribute to the demands of a holistic Aboriginal perspective that is not just about content (Yunkapota \& McGinty, 2009). More importantly they were able to share the relationship that is central in the process, protocols and approach to teaching Aboriginal perspectives to learn about self. Respect and working 
with the Aboriginal communities are the key elements of the relationship that 'permits' the preservice teachers to invoke the Aboriginal way of knowing and learning with Country.

The inceptive relationship within the subject through the Mingadhuga Mingayung approach (McKnight, 2013) has the potential to disrupt cultural barriers of communication and understanding. The research described in this paper has demonstrated how preservice teachers expressed and welcomed the ancient time-honoured skill from Country and engaged in respectful reciprocal relationships to communicate with Country. Furthermore, the research emphasises the imperative of centring Aboriginal Country in the Aboriginal-non-Aboriginal tripartation (McKnight, 2103) to enhance effective Aboriginal community, school and teacher partnerships.

The matter of gender needs to be considered in more detail in this story as it is a way to deepen the understanding of Country and community partnerships. Country, like people is gendered and how gender is observed today is crucial in the reculturalisation of people with Country. While the question of understanding how gender was colonised is important to investigate, this was not a focus of the study. As such it is not explored in detail in this paper, but rather some key considerations are briefly explained to help the reader contextualise how gender can potentially be reculturalised.

The Mountain, Gulaga is female as she birthed the first Yuin people; this does not mean the Mountain is a woman's Mountain only. The story Gulaga holds is the Yuin Creation Story that involves both females and males. The colonised corruption of gendered understandings is how Country has been 
colonised further on a gendered level. As a male, I am also female as I come from the Mother; just as a woman is born of the Mother she is also male in her creation. The part of the experience that is influenced by gendered energy is how the storyteller relates his or her own story to the teachings on and off the Mountain. As a male my gender would have played a significant role in the experience and how the elective subject was taught. In this way the individual story teller's influence can be understood as having consequences for the overall preservice teachers' experience. Importantly, despite these influences of the storyteller, the important outcome is that the core concept of Country as teacher remains intact as the Mother is always put first: reculturalisation.

If reculturalisation is going to occur preservice teachers must be provided with the opportunity to initiate Aboriginal based relationships of knowing and learning early in their career. As the NSW Department of Education and Training and Aboriginal Education Consultative Group Incorporated (2004) report states, “Aboriginal parents and community members strongly stated that they want their children to be successful in both the Aboriginal and nonAboriginal worlds and contribute positively to both" (p. 68). Changing preservice teachers ways of thinking about Aboriginal perspectives can lead to more meaningful cultural engagement of learning with 'all' of the local community(ies) members of Country in the school context. A change to a Country centred approach will take a long time but eventually it will help to simplify the Aboriginal educational context for all stakeholders.

The elective subject allowed Aboriginal stakeholders to reculturalise the educational landscape. At the same time it gave preservice teachers the 
opportunity to initiate an examination of self in relation to decolonising the colonial 'othering' of separation that complicates Western teaching practice for Aboriginal students. Preservice teachers becoming aware of Aboriginal ways of knowing, learning and behaving can therefore have the opportunity to create a central space in the Western education system for Country to contribute in the education of all students. Learning how to care for Country from a oneness position is taking care of yourself. Feeling this on a deep level and continuously experiencing Country as teacher is a great skill to learn. Consequently the closing of the educational gap is not only in one direction towards non-Aboriginal ways of knowing and learning; it is shared. 


\section{References}

Bawaka Country including Suchet-Pearson, S., Wright, S., Lloyd, K., \& Burarrwanga, L. (2013). Caring as Country: Towards an ontology of cobecoming in natural resource management. Asia Pacific Viewpoint, 54(2), pp. 185-197.

Bessarab, B. \& Ng'andu, B. (2010) Yarning about Yarning as a Legitimate Method in Indigenous Research. International Journal of Critical Indigenous Studies, 3(1), pp. 37-50.

Black, C. (2011). Maturing Australia through Australian Aboriginal Narrative Law, The South Atlantic Quarterly, 110(2), pp. 347-362.

Block, P. \& Ebooks Corporation (2009). Community: the structure of belonging. Berrett-Koehler Publishers, San Francisco.

Craven, R. G., Halse, C., Marsh, H. W., Mooney, J. \& Wilson-Miller, J. (2005). Teaching the teachers mandatory Aboriginal Studies. Volume II, Case studies of exemplary practice in preservice teacher education. Department of Education, Science and Training. Commonwealth of Australia, Canberra, ACT.

Geia, L.K., Hayes, B. \& Usher, K. (2013). Yarning/Aboriginal storytelling: towards an understanding of an Indigenous perspective and its implications for research practice. Contemporary Nurse, 46(1), pp. 13-17.

Guyula, Y., Gotha, K., Gurruwiwi, D. \& Christie, M. (2010). The Ethics of Teaching from Country. Australian Aboriginal Studies, 2, pp. 69-80. 
Harrison, N. (2012). Aborigines of the Imaginary: Applying Lacan to Aboriginal Education, Asia-Pacific Journal of Teacher Education, 40(1), pp. $5-14$.

Harrison, M. D. \& McConchie, P. (2009). My people's Dreaming: an Aboriginal elder speaks on life, land, spirit and forgiveness. Warriewood, N.S.W, Finch Publishing.

Hughes, P. (1999). Indigenous education: national imperatives, partnerships \& action: outcomes from a national issues forum. 3-5 November 1999, Deakin West, ACT: Australian College of Education, 1999, p.1.

Kwaymullina, A. \& Kwaymullina, B. (2010). Learning to read the signs: law in an Indigenous reality. Journal of Australian Studies, 34(2), pp. 195-208.

Lowe, K. \& Yunkaporta, T. (2013). The inclusion of Aboriginal and Torres Strait Islander content in the Australian National Curriculum: A cultural, cognitive and socio-political evaluation. Curriculum Perspectives, 33(1), pp. $1-14$.

McRae, D., Ainsworth, G., Cumming, J., Hughes, P., Mackay, T., Price, K., Rowland, M., Warhurst, J., Woods, D. \& Zbar, V. (2000). What works? Explorations in improving outcomes for Indigenous students. Commonwealth Department of Education, Canberra.

Mellor, S. \& Corrigan, M. (2004). The Case for Change: A review of contemporary research on Indigenous education outcomes. ACER Press, Camberwell, Vic. Retrieved from http://research.acer.edu.au/aer/7 
Munns, G., Martin, A. \& Craven, R. (2008). To free the spirit? : motivation and engagement of Indigenous students. Australian Journal of Indigenous Education, 37, pp. 98-107.

Mooney, J., Hals, C. \& Craven, R.G. (2003). Teaching the Teachers Aboriginal Studies: Illustrating Successful Strategies. NZARE AARE Conference Papers, Auckland NZ. Retrieved from http://www.aare.edu.au/03pap/moo03783.pdf

McKnight, A. (2013). Mingadhuga Mingayung: Respecting Country through Mother Mountain's stories to share her cultural voice in Western Academic Structures. Education, Philosophy and Theory. Published Online: 16 Dec 2013.

McKnight, J., Block, P. \& Ebooks Corporation (2010). The abundant community: awakening the power of families and neighbourhoods. American Planning Association, San Francisco, Calif.

New South Wales Institute of Teachers (2007). Initial Teacher Education Programs: Supplementary Documentation for Program Approval (Mandatory Areas). NSW Institute of Teachers

New South Wales Department of Education and Training \& NSW Aboriginal Education Consultative Group (2004). The report of the review of Aboriginal education: Yanigurra Muya : Ganggurrinyma Yaarri, Guurulaw Yirringin.gurray $=$ freeing the spirit $:$ dreaming an equal future . Department of Education and Training, Darlinghurst, N.S.W. 
Smith. L. \& Ebooks Corporation (2012). Decolonizing methodologies: research and indigenous peoples. Zed Books, London.

Smith L. (1999). Decolonizing methodologies: Research and indigenous peoples. London: Zed Books Ltd

Wright, S., Lloyd, K., Suchet-Peason, S., Burarrwanga, L. Tofa, M. \& Bawaka Country (2012). Telling Stories in, through and with Country: engaging with Indigenous and more-than-human methodologies at Bawaka, NE Australia. Journal of Cultural Geography, 29(1), pp. 39-60.

Yunkaporta, T. \& McGinty, S. (2009). Reclaiming aboriginal knowledge at the cultural interface. The Australian Educational Researcher 36(2), pp. 5572. 
i Bakawa Country is in north east Arnhem Land (Bakawa Country, et al. 2012). 